\title{
Effect of Oxygen and Hydrogen Peroxide on the Photocatalytic Degradation of Monochlorobenzene in $\mathrm{TiO}_{2}$ Aqueous Suspension
}

\author{
Dyi-Hwa Tseng, ${ }^{1}$ Lain-Chuen Juang, ${ }^{2}$ and Hsin-Hsu Huang ${ }^{1}$ \\ ${ }^{1}$ Graduate Institute of Environmental Engineering, National Central University, Jhongli 32001, Taiwan \\ ${ }^{2}$ Department of Environmental Engineering and Green Environment $R$ \& D Center, Vanung University, Jhongli 32061, Taiwan
}

Correspondence should be addressed to Lain-Chuen Juang, lcjuang@vnu.edu.tw

Received 1 June 2012; Accepted 21 August 2012

Academic Editor: Meenakshisundaram Swaminathan

Copyright (C) 2012 Dyi-Hwa Tseng et al. This is an open access article distributed under the Creative Commons Attribution License, which permits unrestricted use, distribution, and reproduction in any medium, provided the original work is properly cited.

\begin{abstract}
The influences of oxygen and hydrogen peroxide $\left(\mathrm{H}_{2} \mathrm{O}_{2}\right)$ on the degradation and mineralization of monochlorobenzene (MCB) during $\mathrm{UV} / \mathrm{TiO}_{2}$ process were investigated. Experimental results indicated that oxygen was a determining parameter for promoting the photocatalytic degradation. The presence of oxygen reduced the illumination time needed for the complete decay of MCB from 240 to $120 \mathrm{~min}$. The photocatalytic degradation of $\mathrm{MCB}$ in $\mathrm{UV} / \mathrm{TiO}_{2} / \mathrm{O}_{2}$ photocatalysis followed a simplified two-step consecutive kinetics. The rate constants of degradation $\left(k_{1}\right)$ and mineralization $\left(k_{2}\right)$ were increased from 0.016 to $0.046 \mathrm{~min}^{-1}$ and from 0.001 to $0.006 \mathrm{~min}^{-1}$, respectively, as the initial concentration of dissolved oxygen (DO) was increased from 1.6 to $28.3 \mathrm{mg} \mathrm{L}^{-1}$. Owing to the fact that $\mathrm{H}_{2} \mathrm{O}_{2}$ acted as an electron and hydroxyl radicals $(\cdot \mathrm{OH})$ scavenger, the addition of $\mathrm{H}_{2} \mathrm{O}_{2}$ should in a proper dosage range to enhance the degradation and mineralization of $\mathrm{MCB}$. The optimal $\mathrm{H}_{2} \mathrm{O}_{2}$ dosage for $\mathrm{MCB}$ degradation was $22.5 \mathrm{mg} \mathrm{L}{ }^{-1}$, whereas the most efficient $\mathrm{H}_{2} \mathrm{O}_{2}$ dosage for MCB mineralization was $45.0 \mathrm{mg} \mathrm{L}^{-1}$. In order to minimize the adverse effects of higher $\mathrm{H}_{2} \mathrm{O}_{2}$ dosage, including the capture of $\cdot \mathrm{OH}$ radicals and competitive adsorption, and to improve the photocatalytic degradation of $\mathrm{MCB}$, the sequential replenishment of $\mathrm{H}_{2} \mathrm{O}_{2}$ was suggested. For the stepwise addition of a total $\mathrm{H}_{2} \mathrm{O}_{2}$ dosage of $45.0 \mathrm{mg} \mathrm{L}{ }^{-1}$, a complete destruction of MCB was observed within 120 min of irradiation. Additionally, the mineralization efficiency was about $87.4 \%$ after 240 min of illumination time.
\end{abstract}

\section{Introduction}

During last several decades, the control of organic pollutants has received much attention for its considerable amount and variety. However, the conventional biological, physical, and chemical technologies are ineffective and limitative toward the destruction of toxic and recalcitrant organic pollutants. Heterogeneous photocatalysis, one of the so-called Advanced Oxidation Processes (AOPs), offers an advanced oxidation capable of pollutant abatement $[1,2]$. Many researchers have concluded that the $\mathrm{UV} / \mathrm{TiO}_{2}$ process is a promising technology for the degradation and mineralization of organic substrates to harmless final products in air and water media [3-6].

The mechanism of the $\mathrm{UV} / \mathrm{TiO}_{2}$ process has been discussed extensively in the literature [7-9]. When $\mathrm{TiO}_{2}$ is irradiated with light energy equal to or higher than its band-gap, an electron $\left(\mathrm{e}^{-}\right)$can be excited from the valence band to the conduction band and leaving a hole $\left(\mathrm{h}^{+}\right)$in the valence band

$$
\begin{aligned}
\mathrm{TiO}_{2}+\mathrm{UV} & \longrightarrow \mathrm{h}^{+}+\mathrm{e}^{-} \\
\mathrm{h}^{+}+\mathrm{OH}^{-} / \mathrm{H}_{2} \mathrm{O} & \longrightarrow \cdot \mathrm{OH} / \cdot \mathrm{OH}+\mathrm{H}^{+} \\
\mathrm{e}^{-}+\mathrm{h}^{+} & \longrightarrow \text { heat }
\end{aligned}
$$

If charge separation is maintained, the paired $\mathrm{e}^{-}-\mathrm{h}^{+}$may migrate to the surface of the photocatalyst. In aqueous phase, the photoinduced $\mathrm{h}^{+}$is apparently able to oxidize surface hydroxyl groups or surface-bond water molecules to produce highly reactive and nonselective hydroxyl radicals $(\cdot \mathrm{OH})$ (2). The $\cdot \mathrm{OH}$ radicals are considered to be the dominant oxidizing species contributing to the photocatalytic degradation of organic substrates [10-12]. Nevertheless, the $\mathrm{e}^{-}$can 
recombine with the $\mathrm{h}^{+}(3)$, causing a decrease in the availability of the photoinduced $\mathrm{h}^{+}[13,14]$. Without electron acceptors, the limitation attributed to the recombination of $\mathrm{e}^{-}-\mathrm{h}^{+}$pairs would reduce the photocatalytic efficiency and cause radiation energy loss. Therefore, suppressing the recombination of $\mathrm{e}^{-}-\mathrm{h}^{+}$pairs is an important consideration in enhancing the performance of photocatalytic degradation.

In this study, both oxygen and hydrogen peroxide $\left(\mathrm{H}_{2} \mathrm{O}_{2}\right)$ were selected as electron acceptors. Monochlorobenzene (MCB), one of the hydrophobic and volatile organic compounds (VOCs), was chosen as a model compound. The objectives of the present work were to evaluate the effect of oxygen and $\mathrm{H}_{2} \mathrm{O}_{2}$ on the photocatalytic degradation of $\mathrm{MCB}$. The change in the concentration of $\mathrm{MCB}$ with various oxygen concentrations and $\mathrm{H}_{2} \mathrm{O}_{2}$ dosages was examined. Additionally, the extent of mineralization was also estimated by measuring the concentration of total organic carbon (TOC) in MCB solution.

\section{Materials and Methods}

2.1. Materials. Anatase $\mathrm{TiO}_{2}$ powder with a specific BET surface area of $9.3 \mathrm{~m}^{2} \mathrm{~g}^{-1}$ and a primary particle size of $150 \mathrm{~nm}$ was purchased from Acros Organics and used as received. Reagent grade $\mathrm{MCB}\left(\mathrm{C}_{6} \mathrm{H}_{5} \mathrm{Cl}, \mathrm{MW}=112.56\right.$, density $=1.106 \mathrm{~g} \mathrm{~mL}^{-1}$, vapor pressure $=12 \mathrm{~mm} \mathrm{Hg}$ at $25^{\circ} \mathrm{C}$, and water solubility $=494 \mathrm{mg} \mathrm{L}^{-1}$ at $25^{\circ} \mathrm{C}$ ) with a purity over 99\% was obtained from Merck. $\mathrm{H}_{2} \mathrm{O}_{2}$ (30\%) was obtained from Fluka Chemical. Other chemicals used for analysis, including acetonitrile, acetic acid, potassium hydrogen phthalate, phosphoric acid, and sodium peroxydisulfate were of analytical grade. Pure $\mathrm{N}_{2}$ and $\mathrm{O}_{2}$ gases and air were used to adjust the initial dissolved oxygen (DO) concentration to the desired levels. Deionized water was employed for solution preparation.

2.2. Experimental Apparatus and Procedure. A hollow cylindrical photoreactor with a working capacity of $2.5 \mathrm{l}$ and equipped with a water jacket was used in this study. Cooling water from a thermostatic bath (TUNGTEC BL-20) was circulated through the photoreactor jacket to keep the temperature at $30^{\circ} \mathrm{C}$. Irradiation was performed using a $15 \mathrm{~W}$ blacklight lamp (F15T8 BLB, UVP) with a maximum emission at $365 \mathrm{~nm}$. The UV lamp was vertically immersed in a quartz tube placed in the center of the photoreactor. The light intensity inside the photoreactor, as measured by potassium ferrioxalate actinometry, was $5.68 \mu$ Einstein $\mathrm{s}^{-1}$. The reaction mixture was continuously agitated by a magnetic stirrer to keep the $\mathrm{TiO}_{2}$ particles suspended.

Two series of experiments were carried out to examine the effects of oxygen and $\mathrm{H}_{2} \mathrm{O}_{2}$ on the photocatalytic degradation of MCB. Prior to MCB solution preparation, all deionized water was first purged by $\mathrm{N}_{2}$ gas for $30 \mathrm{~min}$ to minimize the amount of DO. Subsequently, the deionized water was purged with either air or $\mathrm{O}_{2}$ gas to obtain the predetermined DO concentration. The initial concentration of MCB was fixed at $0.1 \mathrm{mM}$ and the $\mathrm{TiO}_{2}$ dosage was $1.0 \mathrm{~g} \mathrm{~L}^{-1}$ unless otherwise stated. The initial $\mathrm{pH}$ of solution was adjusted to 7 by adding an appropriate volume of dilute $\mathrm{NaOH}$ or $\mathrm{HNO}_{3}$ solutions. After 30 min of premixing in the dark, the UV lamp was switched on to initiate the photocatalytic degradation.

The experimental procedure for the $\mathrm{H}_{2} \mathrm{O}_{2}$-assisted batch was similar to the oxygen-assisted batch. In this case, the MCB solution was prepared using deionized water that had been deoxygenated by $\mathrm{N}_{2}$ gas. After $\mathrm{TiO}_{2}$ powder was added into the solution, the solution $\mathrm{pH}$ was adjusted to 7 with dilute $\mathrm{NaOH}$ or $\mathrm{HNO}_{3}$ solutions. Prior to irradiation, the suspension was magnetically stirred in the dark for $30 \mathrm{~min}$. After the addition of $\mathrm{H}_{2} \mathrm{O}_{2}$ into the suspension, the UV lamp was turned on.

At given irradiation time intervals, samples were withdrawn from the irradiated suspension. These collected samples were immediately centrifuged and filtered through a $0.22 \mu \mathrm{m}$ Millipore filter for further analysis.

2.3. Analytical Methods. The residual MCB measurement was carried out by HPLC (Biotronik HPLC BT 7900) equipped with a Linear UVIS 200 UV detector and an ODS2 C18 column (length $25 \mathrm{~cm}$, inner diameter $4.6 \mathrm{~mm}$ ). The mobile phase was composed of acetonitrile (70\%), water (29\%), and acetic acid (1\%) and the flow rate was kept at $1.5 \mathrm{~mL} \mathrm{~min}{ }^{-1}$. The detection wavelength selected for detecting MCB was $265 \mathrm{~nm}$. A TOC analyzer (O. I. Analytical Model 700) equipped with a nondispersive infrared detector (NDIR) was employed to monitor the concentration of TOC. The DO concentration was quantified by an oxygen membrane electrode (Oxi 320, WTW).

\section{Results and Discussion}

3.1. Direct Photolysis and $\mathrm{H}_{2} \mathrm{O}_{2}$-Assisted Photolysis. Two preliminary experiments were carried out to estimate the contribution of direct photolysis and $\mathrm{H}_{2} \mathrm{O}_{2}$-assisted photolysis for the removal of MCB. The variation in the MCB concentration during irradiation can be seen in Figure 1. For the direct photolysis, there was about $42.8 \%$ degradation of MCB after $240 \mathrm{~min}$ of illumination time. This result implied that the UV light had evident contribution on the degradation of $\mathrm{MCB}$ which was in agreement with the observation reported by other researcher [15]. The change in the MCB concentration fitted an exponential decay curve, suggesting the direct photolysis of MCB followed the pattern of pseudo first-order kinetics. A linear regression was obtained with natural logarithmic normalized concentration against illumination time. The degradation rate constant was calculated to be $0.002 \mathrm{~min}^{-1}$.

In order to evaluate the degradation ability of $\mathrm{H}_{2} \mathrm{O}_{2}$ assisted photolysis, an irradiation experiment was conducted under the condition of $\mathrm{H}_{2} \mathrm{O}_{2}$ dosage equal to $22.5 \mathrm{mg} \mathrm{L}^{-1}$. Corresponding to the obtained experimental result recorded in Figure 1, it was found that the concentration of $\mathrm{MCB}$ decreased gradually during the period of irradiation. The extent of MCB degradation in the $\mathrm{H}_{2} \mathrm{O}_{2}$-assisted photolysis within $240 \mathrm{~min}$ of irradiation was approximately $60.2 \%$ and the pseudo first-order degradation rate constant was 


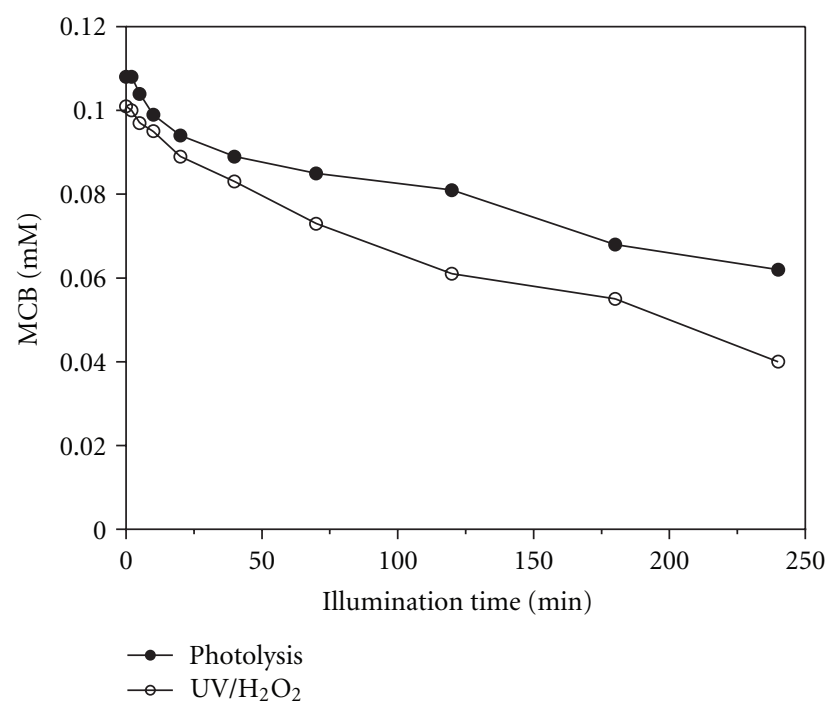

FIGURE 1: Direct photolysis and $\mathrm{H}_{2} \mathrm{O}_{2}$-assisted photolysis of MCB.

$0.004 \mathrm{~min}^{-1}$. The typical time-dependent MCB concentration in the presence of both UV light and $\mathrm{H}_{2} \mathrm{O}_{2}$ was similar to that under the UV irradiation only. It was stated that $\mathrm{H}_{2} \mathrm{O}_{2}$ has an extremely low absorption at UV light of $365 \mathrm{~nm}$ [16], therefore, the generation of $\cdot \mathrm{OH}$ radicals due to the photolysis of $\mathrm{H}_{2} \mathrm{O}_{2}$ would be insignificant. As a result, the observable MCB decay can mainly be ascribed to the direct photolysis. Moreover, the additional MCB degradation can be explained by the oxidative ability of $\mathrm{H}_{2} \mathrm{O}_{2}$.

\section{2. $\mathrm{UV} / \mathrm{TiO}_{2} / \mathrm{O}_{2}$ Photocatalysis}

3.2.1. Degradation of $M C B$. The dependency of the photocatalytic degradation of MCB on the initial DO concentration was studied in the range from 1.6 to $28.3 \mathrm{mg} \mathrm{L}^{-1}$. Typical time-dependent $\mathrm{MCB}$ concentration during photocatalytic degradation is illustrated in Figure 2(a). As can be seen, when $\mathrm{TiO}_{2}$ suspension was exposed to UV light, the MCB concentration decreased markedly with illumination time in comparison with the same experiment performed in the absence of $\mathrm{TiO}_{2}$. The difference between direct photolysis and $\mathrm{UV} / \mathrm{TiO}_{2} / \mathrm{O}_{2}$ photocatalysis revealed that UV light and $\mathrm{TiO}_{2}$ photocatalyst together had a significant effect on the degradation of $\mathrm{MCB}$. Since $\cdot \mathrm{OH}$ radicals were the key feature of $\mathrm{UV} / \mathrm{TiO}_{2}$ process, the degradation of $\mathrm{MCB}$ was primarily related to the generated $\cdot \mathrm{OH}$ radicals.

Referring to Figure 2(a), the presence of oxygen was contributed to the photocatalytic degradation. Complete destruction of MCB was observed after 240 min of irradiation when the experiment was performed under initial DO concentration equal to $1.6 \mathrm{mg} \mathrm{L}^{-1}$. In addition, for the initial DO concentration of $28.3 \mathrm{mg} \mathrm{L}^{-1}$, the illumination time required for complete decay of $\mathrm{MCB}$ was reduced to $120 \mathrm{~min}$. The depletion of the DO concentration during irradiation, as recorded in Figure 2(b), confirmed that oxygen was involved in the photocatalytic degradation. Accordingly, the improvement of the degradation of $\mathrm{MCB}$, which is related to the increasing initial DO concentration, can be attributed to the fact that oxygen acted as electron acceptor to trap the photoinduced $\mathrm{e}^{-}[17,18]$

$$
\begin{gathered}
\mathrm{O}_{2}+\mathrm{e}^{-} \longrightarrow \mathrm{O}_{2} \cdot{ }^{-} \\
\mathrm{O}_{2} \cdot{ }^{-}+\mathrm{H}^{+} \longrightarrow \mathrm{HO}_{2} \cdot \\
\mathrm{HO}_{2} \cdot+\mathrm{HO}_{2} \cdot \longrightarrow \mathrm{H}_{2} \mathrm{O}_{2}+\mathrm{O}_{2} \\
\mathrm{O}_{2} \cdot{ }^{-}+\mathrm{HO}_{2} \cdot+\mathrm{H}^{+} \longrightarrow \mathrm{H}_{2} \mathrm{O}_{2}+\mathrm{O}_{2}
\end{gathered}
$$

Through the reduction of oxygen with $\mathrm{e}^{-}$, reactive superoxide radical anions $\left(\mathrm{O}_{2} \cdot{ }^{-}\right)$was produced (4). Simultaneously, the $\mathrm{e}^{-}-\mathrm{h}^{+}$pair recombination was restrained. Stabilizing the primary carrier led to promote the generation of $\cdot \mathrm{OH}$ radicals. Moreover, other oxidizing species such as $\mathrm{HO}_{2}$. and $\mathrm{H}_{2} \mathrm{O}_{2}$ were also formed (5)-(7). It was believed that additional $\cdot \mathrm{OH}$ radicals would be generated through sequential reactions [11, 19-21]. Consequently, an increase in the DO concentration would accelerate the degradation of MCB.

3.2.2. Mineralization of $M C B$. The decay of TOC during photocatalytic degradation was monitored to evaluate the mineralization of MCB. From the plot shown in Figure 2(c), the improvement of the mineralization of $\mathrm{MCB}$ in the presence of oxygen was observed. The mineralization efficiency increased from 42.6 to $93.1 \%$ within 240 min of irradiation as initial DO concentration varied from 1.6 to $28.3 \mathrm{mg} \mathrm{L}^{-1}$. Similar observations have been reported in the literature for other model compounds [22-24].

For the initial DO concentrations of 17.9 and $28.3 \mathrm{mg} \mathrm{L}^{-1}$, there were still measurable DO concentrations after $240 \mathrm{~min}$ of illumination time. Since there was sufficient oxygen in the photocatalytic system, the TOC decreased abidingly during photocatalytic degradation. Moreover, besides the electron acceptor function, oxygen can also participate in the oxidative reaction to promote the mineralization of organic substrates and intermediates $[25,26]$. Consequently, the depression of TOC decay was ascribed to the lack of oxygen involved in the photocatalytic degradation afterward in the case of lower initial DO concentration.

A comparison of Figures 2(a) and 2(c) indicated that the TOC decayed with illumination time in parallel with the MCB degradation. However, it should be noted that complete disappearance of MCB occurred within 120 to $240 \mathrm{~min}$ of irradiation under various initial DO concentrations, whereas residual TOC was still observed. This phenomenon implied that transient organic intermediates were likely to present in the photocatalytic system.

3.2.3. Two-Step Consecutive Kinetics. Based on the total organic carbon concentration in the photocatalytic system, the mass balance can be expressed as $[27,28]$

$$
[\mathrm{TOC}]_{t}=[\mathrm{MCB}]_{c, t}+[\text { Inter } \cdot]_{c, t},
$$

where $[\mathrm{TOC}]_{t}$ is the total organic carbon concentration in the system, $[\mathrm{MCB}]_{c, t}$ is the carbon concentration in the $\mathrm{MCB}$ 


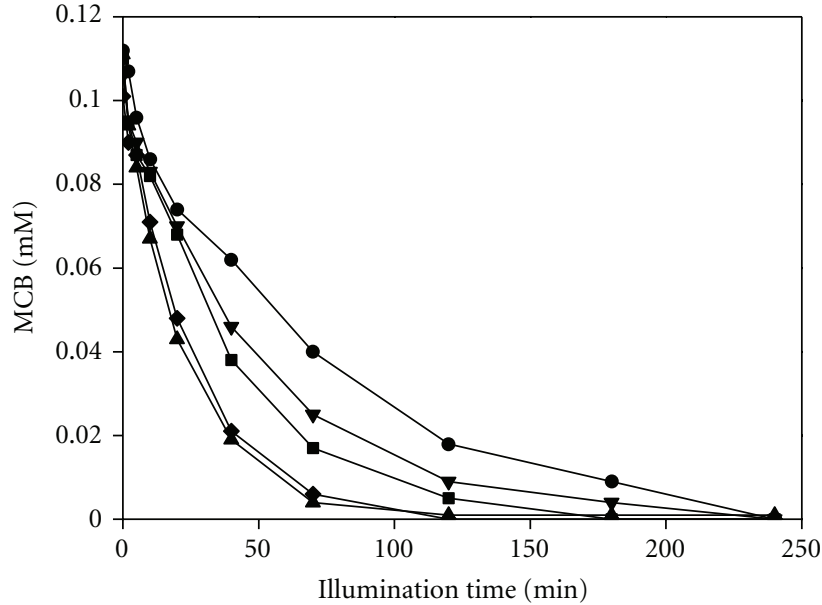

(a)

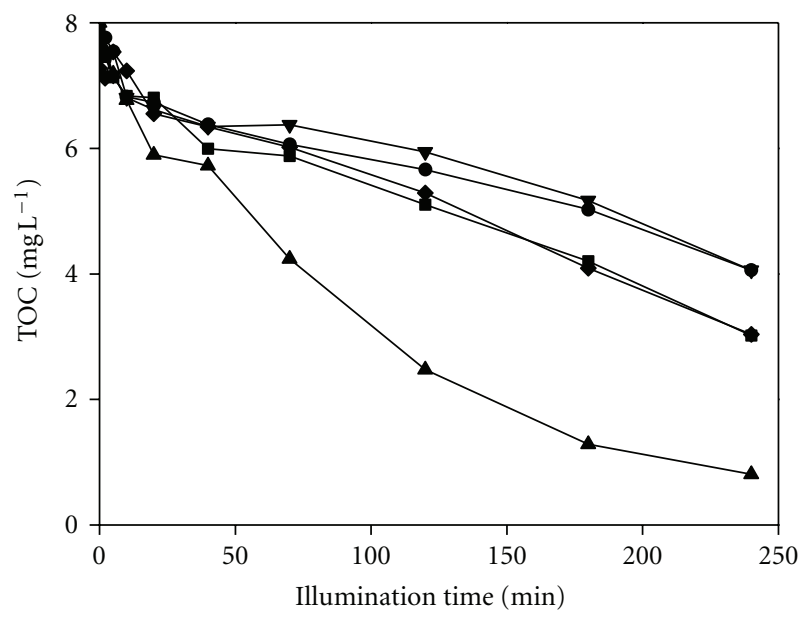

(c)

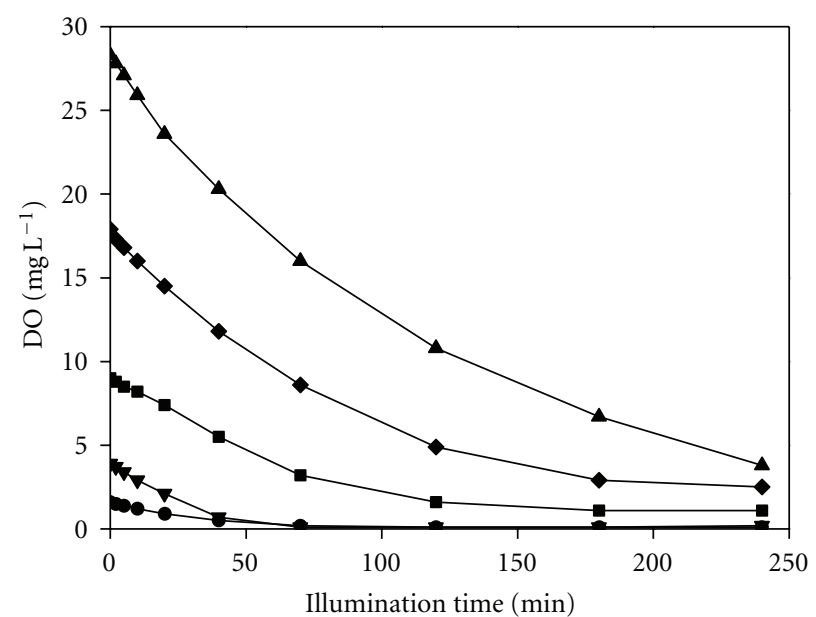

(b)

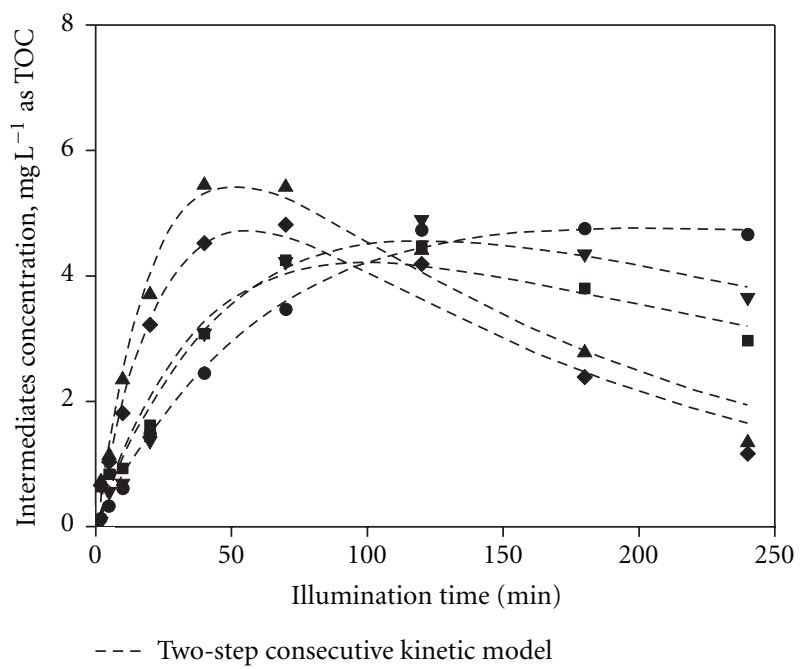

(d)

FIGURE 2: Concentration profiles of (a) MCB, (b) DO, (c) TOC, and (d) intermediates during photocatalytic degradation of MCB at various initial DO concentrations: $(\bullet) 1.6 \mathrm{mg} \mathrm{L}^{-1},(\boldsymbol{\nabla}) 3.9 \mathrm{mg} \mathrm{L}^{-1},(\boldsymbol{\square}) 9.0 \mathrm{mg} \mathrm{L}^{-1}$, (४) $17.9 \mathrm{mg} \mathrm{L}^{-1}$, and $(\mathbf{\Delta}) 28.3 \mathrm{mg} \mathrm{L}^{-1}$.

at time $t$, and $[\text { Inter } \cdot]_{c, t}$ is the carbon concentration in the intermediates at time $t$. Correspondingly, the carbon concentration in the intermediates can be determined from the concentrations of MCB and TOC. Figure 2(d) illustrates the variation of carbon concentration in the intermediates for different initial DO concentration during the photocatalytic degradation of MCB. As can be seen, the intermediates accumulated first and decomposed thereafter.

Since the mineralization of MCB occurs through the intermediates, a simplified two-step consecutive kinetics can be used to describe the photocatalytic degradation $[29,30]$

$$
\mathrm{MCB}_{\longrightarrow}^{k_{1}} \text { Intermediates } \stackrel{k_{2}}{\longrightarrow} \text { ultimate product }
$$

where $k_{1}$ is the degradation rate constant of MCB and $k_{2}$ is the mineralization rate constant of the intermediates. The ultimate product of the photocatalytic degradation can be $\mathrm{CO}_{2}, \mathrm{H}_{2} \mathrm{O}$, and relevant inorganic ions. Each step in (9) is assumed to be a first-order and irreversible reaction. Applying the two-step consecutive kinetics, the carbon concentrations in the MCB and the intermediates can be expressed by

$$
\begin{aligned}
{[\mathrm{MCB}]_{c, t} } & =[\mathrm{MCB}]_{c, o} e^{-k_{1} t} \\
{[\text { Inter } \cdot]_{c, t} } & =\frac{k_{1}[\mathrm{MCB}]_{c, o}}{k_{2}-k_{1}}\left(e^{-k_{1} t}-e^{-k_{2} t}\right) .
\end{aligned}
$$

Accordingly, the two rate constants $k_{1}$ and $k_{2}$ can be derived from the disappearance of MCB and the intermediates.

As listed in Table 1, the increase in the value of $k_{1}$ was proportional to the initial DO concentration. The enhancement of $k_{1}$ was about 3 times higher when the initial DO concentration was $28.3 \mathrm{mg} \mathrm{L}^{-1}$ rather than $1.6 \mathrm{mg} \mathrm{L}^{-1}$. Take the calculated $k_{1}$ and the determined [Inter $]_{c, t}$ into (11), 
TABle 1: Determination of the two-step consecutive kinetic constant for the photocatalytic degradation of MCB at different DO concentration.

\begin{tabular}{|c|c|c|c|c|}
\hline DO concentration, $\mathrm{mg} \mathrm{L}^{-1}$ & $k_{1}, \min ^{-1}$ & $R^{2}$ & $k_{2}, \min ^{-1}$ & $R^{2}$ \\
\hline 1.6 & 0.016 & 0.9915 & 0.001 & 0.9843 \\
\hline 3.9 & 0.020 & 0.9884 & 0.003 & 0.9787 \\
\hline 9.0 & 0.025 & 0.9940 & 0.003 & 0.9681 \\
\hline 17.9 & 0.038 & 0.9975 & 0.007 & 0.9591 \\
\hline 28.3 & 0.046 & 0.9977 & 0.006 & 0.9685 \\
\hline
\end{tabular}

TABLE 2: Determination of the two-step consecutive kinetic constant for the photocatalytic degradation of $\mathrm{MCB}$ at different $\mathrm{H}_{2} \mathrm{O}_{2}$ dosage.

\begin{tabular}{lcccc}
\hline $\mathrm{H}_{2} \mathrm{O}_{2}$ dosage, $\mathrm{mg} \mathrm{L}^{-1}$ & $k_{1}, \mathrm{~min}^{-1}$ & $R^{2}$ & $k_{2}, \mathrm{~min}^{-1}$ & 0.002 \\
\hline 5.6 & 0.018 & 0.9966 & 0.002 & 0.9836 \\
11.2 & 0.023 & 0.9932 & 0.002 & 0.8682 \\
22.5 & 0.026 & 0.9956 & 0.001 & 0.8519 \\
45.0 & 0.024 & 0.9872 & $<<0.001$ & 0.9631 \\
78.0 & 0.011 & 0.9972 & & 0.2 \\
\hline
\end{tabular}

the value of mineralization rate constant $k_{2}$ was obtained. It was evident that the mineralization rate constant depended on the initial DO concentration. The value of $k_{2}$ increased with increasing initial DO concentration to a certain level and thereafter remained almost constant. The $k_{2}$ increased 8 times when the initial DO concentration was increased to $17.9 \mathrm{mg} \mathrm{L}^{-1}$ rather than $1.6 \mathrm{mg} \mathrm{L}^{-1}$. Interestingly, the values of $k_{2}$ were lower than those of $k_{1}$, this revealed that the mineralization may be the rate-limiting step in the photocatalytic degradation of MCB. Therefore, prolonged illumination time would be reasonable for complete mineralization.

\section{3. $\mathrm{UV} / \mathrm{TiO}_{2} / \mathrm{H}_{2} \mathrm{O}_{2}$ Photocatalysis}

3.3.1. Degradation of $M C B$. According to its high oxidation potential and electrophilic, $\mathrm{H}_{2} \mathrm{O}_{2}$ is a stronger electron acceptor than oxygen [31-33]. A series of experiments were conducted with deoxygenated $\mathrm{TiO}_{2}$ suspension in order to evaluate the effect of $\mathrm{H}_{2} \mathrm{O}_{2}$ dosage on the photocatalytic degradation of MCB. The examined range of $\mathrm{H}_{2} \mathrm{O}_{2}$ dosage was varied from 5.6 to $78.0 \mathrm{mg} \mathrm{L}^{-1}$. From the typical temporal file exhibited in Figure 3(a), it can be seen that the degradation of MCB was sensitive to the variation of $\mathrm{H}_{2} \mathrm{O}_{2}$ dosage. A pseudo first-order kinetic model was provided to simulate the degradation of MCB. Table 2 summarizes the degradation rate constant $k_{1}$ derived from the gradient of the plot of the natural logarithm of the normalized MCB concentration against the illumination time. When the $\mathrm{H}_{2} \mathrm{O}_{2}$ dosage increased from 5.6 to $22.5 \mathrm{mg} \mathrm{L}^{-1}$ the value of $k_{1}$ increased from 0.018 to $0.026 \mathrm{~min}^{-1}$. A further increase in the $\mathrm{H}_{2} \mathrm{O}_{2}$ dosage from 22.5 to $78.0 \mathrm{mg} \mathrm{L}^{-1}$, however, led to a significant decline in the $k_{1}$ from 0.026 to $0.011 \mathrm{~min}^{-1}$. The optimum $\mathrm{H}_{2} \mathrm{O}_{2}$ dosage for the degradation of MCB was around $22.5 \mathrm{mg} \mathrm{L}^{-1}$ which was similar to that observed by other researchers $[20,34-36]$.
The influence of $\mathrm{H}_{2} \mathrm{O}_{2}$ dosage on the degradation of MCB can be explained in terms of the number of generated - $\mathrm{OH}$ radicals and the capture of $\cdot \mathrm{OH}$ radicals [36-39]. It is well known that $\mathrm{H}_{2} \mathrm{O}_{2}$ can trap photoinduced $\mathrm{e}^{-}$to stabilize the paired $\mathrm{e}^{-}-\mathrm{h}^{+}$

$$
\begin{gathered}
\mathrm{H}_{2} \mathrm{O}_{2}+\mathrm{e}^{-} \longrightarrow \cdot \mathrm{OH}+\mathrm{OH}^{-} \\
\mathrm{H}_{2} \mathrm{O}_{2}+\mathrm{O}_{2} \cdot-\longrightarrow \cdot \mathrm{OH}+\mathrm{OH}^{-}+\mathrm{O}_{2} \\
\mathrm{H}_{2} \mathrm{O}_{2}+\cdot \mathrm{OH} \longrightarrow \mathrm{H}_{2} \mathrm{O}+\mathrm{OH}_{2} \\
\mathrm{HO}_{2} \cdot+\cdot \mathrm{OH} \longrightarrow \mathrm{H}_{2} \mathrm{O}+\mathrm{O}_{2}
\end{gathered}
$$

Additional $\cdot \mathrm{OH}$ radicals could be yielded via the reaction between $\mathrm{H}_{2} \mathrm{O}_{2}$ and $\mathrm{e}^{-}$or $\mathrm{O}_{2}{ }^{-}$(12) and (13). As a result, the addition of $\mathrm{H}_{2} \mathrm{O}_{2}$ into the photocatalytic system was expected to promote the degradation of MCB. Exceeding the optimum dosage, however, the excess $\mathrm{H}_{2} \mathrm{O}_{2}$ would trap the $\cdot \mathrm{OH}$ radicals to form weaker oxidant $\mathrm{HO}_{2} \cdot$ radicals. Accordingly, the capture of $\cdot \mathrm{OH}$ radicals was occurred through (14) and (15). The decline in the $\cdot \mathrm{OH}$ radical concentration, trigged by the higher $\mathrm{H}_{2} \mathrm{O}_{2}$ dosage, restrained the degradation of MCB.

The variation of DO concentration during the $\mathrm{UV} / \mathrm{TiO}_{2} /$ $\mathrm{H}_{2} \mathrm{O}_{2}$ photocatalysis for a variety of $\mathrm{H}_{2} \mathrm{O}_{2}$ dosage is illustrated in Figure 3(b). It was found that the DO concentration increased markedly with illumination time to reach a maximum value and decreased thereafter. The increase in the DO concentration was related to the decomposition of $\mathrm{H}_{2} \mathrm{O}_{2}$ $[39,40]$

$$
2 \mathrm{H}_{2} \mathrm{O}_{2} \longrightarrow \mathrm{H}_{2} \mathrm{O}+\mathrm{O}_{2} \text {. }
$$

Correspondingly, the addition of $\mathrm{H}_{2} \mathrm{O}_{2}$ seemed to act as an oxygen source. The later decrease in the DO concentration implied that the generated oxygen was involved in the mineralization. 


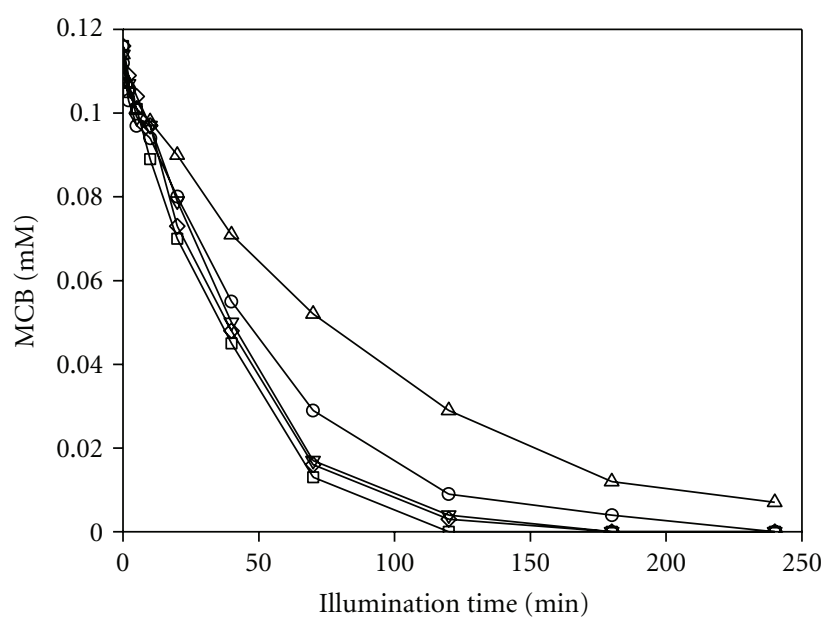

(a)

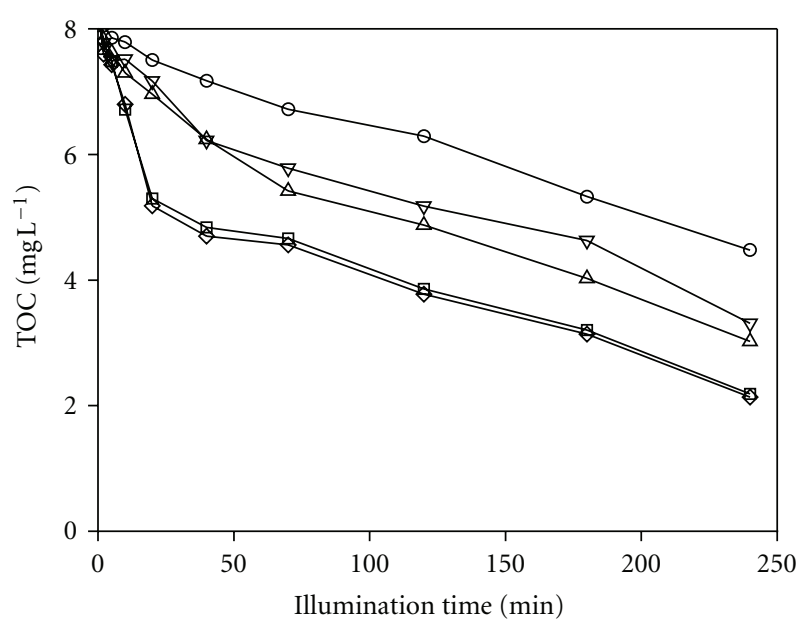

(c)

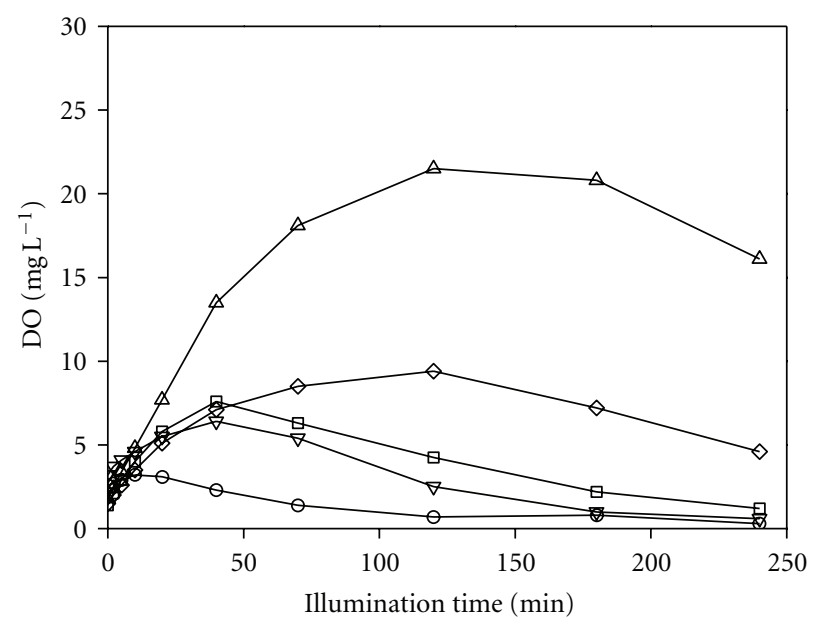

(b)

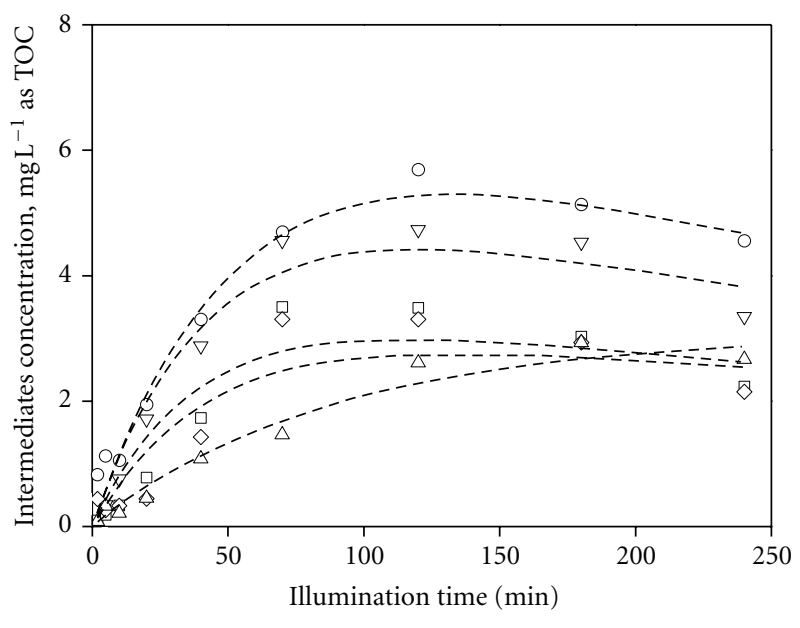

- - - Two-step consecutive kinetic model

(d)

Figure 3: Concentration profiles for (a) MCB, (b) DO, (c) TOC, and (d) intermediates during photocatalytic degradation of MCB at various $\mathrm{H}_{2} \mathrm{O}_{2}$ dosages: $(\bigcirc) 5.6 \mathrm{mg} \mathrm{L}^{-1},(\nabla) 11.2 \mathrm{mg} \mathrm{L}^{-1},(\square) 22.5 \mathrm{mg} \mathrm{L}^{-1},(\diamond) 45.0 \mathrm{mg} \mathrm{L}^{-1}$, and $(\triangle) 78.0 \mathrm{mg} \mathrm{L}^{-1}$.

3.3.2. Mineralization of $M C B$. Similar to the degradation of $\mathrm{MCB}$, the mineralization of $\mathrm{MCB}$ also took place throughout the entire irradiation. Figure 3(c) shows the concentration of TOC as a function of illumination time under various $\mathrm{H}_{2} \mathrm{O}_{2}$ dosages. As can be seen, the extent of TOC decay increased from 44.4 to $74.1 \%$ with $\mathrm{H}_{2} \mathrm{O}_{2}$ dosage increased from 5.6 to $45.0 \mathrm{mg} \mathrm{L}^{-1}$ after $240 \mathrm{~min}$ of irradiation. At higher dosage, however, the mineralization efficiency decreased to $62.5 \%$. Reviewing the result shown in Figure 3(a), there was still observable MCB throughout the entire irradiation period in the case of $\mathrm{H}_{2} \mathrm{O}_{2}$ dosage equal to $78.0 \mathrm{mg} \mathrm{L}^{-1}$. This meant that the constraint on the mineralization efficiency may be ascribed to the competitive MCB.

Based on (8), the carbon concentration in the transient organic intermediates was determined as shown in Figure 3(d). Interestingly, the maximum value of intermediate concentration was decreased when the $\mathrm{H}_{2} \mathrm{O}_{2}$ dosage varied from 5.6 to $78.0 \mathrm{mg} \mathrm{L}^{-1}$. When $\mathrm{H}_{2} \mathrm{O}_{2}$ dosage was $5.6 \mathrm{mg} \mathrm{L}^{-1}$, the intermediates accumulated abidingly to its maximum value of $5.6 \mathrm{mg} \mathrm{L}^{-1}$ as TOC and then decreased. Similarly, the maximum values were $4.7,3.5,3.2$, and $3.0 \mathrm{mg} \mathrm{L}^{-1}$ as TOC in the cases of $\mathrm{H}_{2} \mathrm{O}_{2}$ dosage equal to 11.2, $22.5,45.0$, and $78.0 \mathrm{mg} \mathrm{L}^{-1}$, respectively. The decline in the maximum concentration of the intermediates revealed that some fraction of mineralization was occurred in parallel with the degradation of MCB.

Applying two-step consecutive kinetic model to the determined intermediate concentration, the mineralization rate constant $k_{2}$ was calculated as summarized in Table 2 . It can be seen that the value of $k_{2}$ was decreased with increasing $\mathrm{H}_{2} \mathrm{O}_{2}$ dosage. The highest $k_{2}$ value was $0.002 \mathrm{~min}^{-1}$ under the experimental conditions of $\mathrm{H}_{2} \mathrm{O}_{2}$ dosage equal to 5.6, 11.2 , and $22.5 \mathrm{mg} \mathrm{L}^{-1}$. Notably, when the $\mathrm{H}_{2} \mathrm{O}_{2}$ dosage was $78.0 \mathrm{mg} \mathrm{L}^{-1}$, the determined $k_{2}$ value was lower than 
$0.001 \mathrm{~min}^{-1}$. According to the principle of the two-step consecutive kinetics, the calculation of $k_{2}$ value was depend on the concentration of the intermediates and the value of $k_{1}$. Consequently, the decline of the maximum intermediates concentration as $\mathrm{H}_{2} \mathrm{O}_{2}$ dosage was increased led to a lower $k_{2}$ value.

3.4. Evaluation of Oxygen and $\mathrm{H}_{2} \mathrm{O}_{2}$ as Electron Acceptors. According to its characteristics as electron acceptor and oxidizing agent, the presence of oxygen in photocatalytic system was beneficial for the photocatalytic degradation of MCB. The experimental results confirmed that the photocatalytic degradation of MCB in the presence of oxygen followed a simplified two-step consecutive kinetics. For kinetic analysis, both degradation and mineralization rate constants had been demonstrated to increase with increasing DO concentration. However, this is an important consideration to bear in mind that the DO concentration in contaminated water may be limited and aeration would cause the stripping of volatile organic compound such as MCB.

It is preferential to use $\mathrm{H}_{2} \mathrm{O}_{2}$ where there is a limited availability of oxygen. Considering its hydrophilic property, the $\mathrm{H}_{2} \mathrm{O}_{2}$ would come into contact with the hydroxylated $\mathrm{TiO}_{2}$ particles in aqueous solution and trap the photoinduced $\mathrm{e}^{-}$. Furthermore, $\mathrm{H}_{2} \mathrm{O}_{2}$ could also serve as an oxygen source to improve the mineralization. Excess $\mathrm{H}_{2} \mathrm{O}_{2}$, however, could act as $\cdot \mathrm{OH}$ radical scavenger in the photocatalytic system. Moreover, the $\mathrm{H}_{2} \mathrm{O}_{2}$ may compete with MCB for the active sites of $\mathrm{TiO}_{2}$ particle $[32,41-44]$ to suppress the photocatalytic degradation of MCB. To avoid the capture of . $\mathrm{OH}$ radical and competitive adsorption under high $\mathrm{H}_{2} \mathrm{O}_{2}$ dosage, sequential replenishment of $\mathrm{H}_{2} \mathrm{O}_{2}$ into $\mathrm{UV} / \mathrm{TiO}_{2}$ system was suggested.

Referring to Figure 3, the most efficient degradation was observed where the $\mathrm{H}_{2} \mathrm{O}_{2}$ dosage was $22.5 \mathrm{mg} \mathrm{L}^{-1}$, whereas the optimal $\mathrm{H}_{2} \mathrm{O}_{2}$ dosage for MCB mineralization was $45.0 \mathrm{mg} \mathrm{L}^{-1}$. Accordingly, total dosage of $\mathrm{H}_{2} \mathrm{O}_{2}$ equal to $45.0 \mathrm{mg} \mathrm{L}^{-1}$ was chosen for the evaluation of the photocatalytic degradation of MCB under various $\mathrm{H}_{2} \mathrm{O}_{2}$ addition sequences. In the experiment of stepwise addition of $\mathrm{H}_{2} \mathrm{O}_{2}$, $22.5 \mathrm{mg} \mathrm{L}^{-1}$ of $\mathrm{H}_{2} \mathrm{O}_{2}$ was added into the $\mathrm{TiO}_{2}$ suspension, once before irradiation and again after 40 min of illumination time. As the result illustrated in Figure 4(a), 120 min of irradiation was sufficient for complete elimination of $\mathrm{MCB}$ in the case when a two-step addition was made. On the contrary, $180 \mathrm{~min}$ of illumination time was needed for the one-time addition. The enhancement of the degradation efficiency was correlated to the higher degradation rate constant when the $\mathrm{H}_{2} \mathrm{O}_{2}$ dosage was $22.5 \mathrm{mg} \mathrm{L}^{-1}$ rather than $45.0 \mathrm{mg} \mathrm{L}^{-1}$. Moreover, the second addition of $\mathrm{H}_{2} \mathrm{O}_{2}$ was attributed to sustain the suppression of the $\mathrm{e}^{-}-\mathrm{h}^{+}$pair recombination.

Monitoring the variation of DO concentration during photocatalytic degradation, it was observed that the oxygen accumulated continuously within 120 min of illumination time then decreased thereafter for both cases (Figure 4(b)). The concentration of the intermediates showed a similar tendency as depicted in Figure 4(c). Oxygen generated as a result

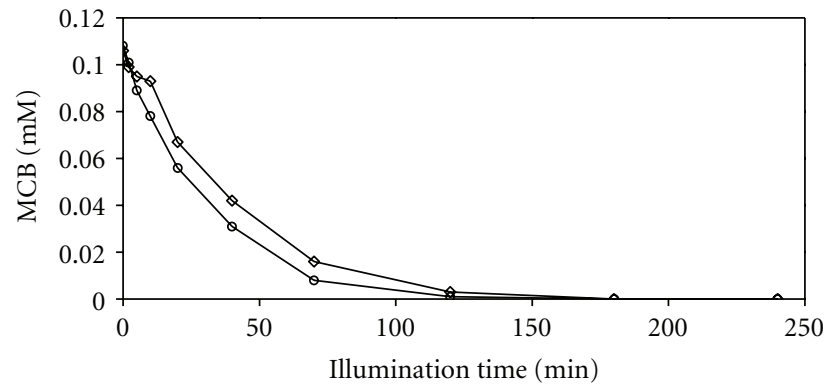

(a)

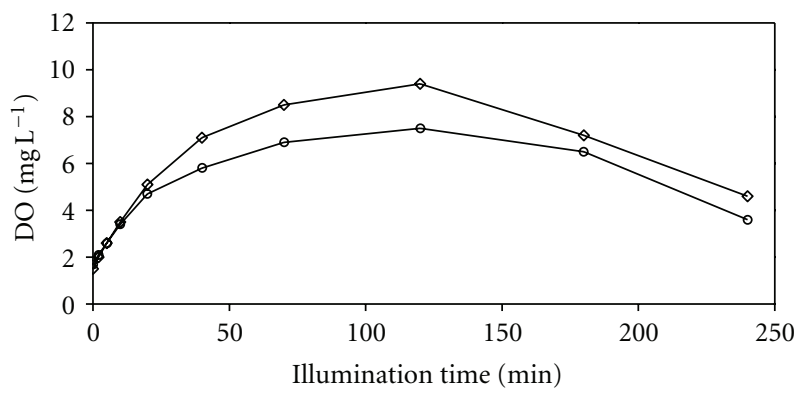

(b)

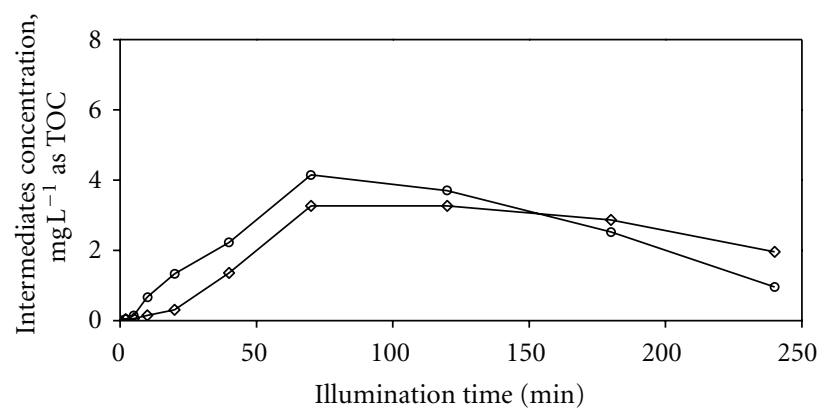

(c)

FIgure 4: Comparison of the photocatalytic degradation of MCB under various $\mathrm{H}_{2} \mathrm{O}_{2}$ : $(\bigcirc)$ two-step addition and $(\diamond)$ one-time addition.

of the decomposition of $\mathrm{H}_{2} \mathrm{O}_{2}$ whereas the accumulation of intermediates was due to the degradation of MCB. According to the effective degradation under the two-step addition of $\mathrm{H}_{2} \mathrm{O}_{2}$, the concentration of intermediates increased faster than that under one-time addition of $\mathrm{H}_{2} \mathrm{O}_{2}$. Furthermore, since oxygen would participate in the mineralization of $\mathrm{MCB}$, both the concentrations of oxygen and intermediates declined afterward. A comparison of the experimental profiles shows that depletion of the intermediates concentration was shaper for the two-step addition of $\mathrm{H}_{2} \mathrm{O}_{2}$ than that for the one-time addition. Correspondingly, after $240 \mathrm{~min}$ of irradiation the mineralization efficiency of MCB in the case of two-step addition of $\mathrm{H}_{2} \mathrm{O}_{2}$ was $87.4 \%$ higher than the value of $74.1 \%$ in the case of one-time addition. The increment in the mineralization efficiency can be explained as due to the restraint of the capture of $\cdot \mathrm{OH}$ radicals, the additional $\cdot \mathrm{OH}$ radicals related with second dose of $\mathrm{H}_{2} \mathrm{O}_{2}$, and the participation of oxygen in photocatalytic degradation. Accordingly, it was evident that the sequential 
replenishment of $\mathrm{H}_{2} \mathrm{O}_{2}$ into $\mathrm{UV} / \mathrm{TiO}_{2}$ system was advisable as a way to improve the efficiency of the photocatalytic degradation.

\section{Conclusions}

The direct photolysis and the oxidative potential of $\mathrm{H}_{2} \mathrm{O}_{2}$ were proven to have slight contribution on the degradation of MCB. Notably, UV light and $\mathrm{TiO}_{2}$ together showed a marked effect. Increasing the DO concentration was beneficial for the photocatalytic degradation of MCB. Correspondingly, the degradation and mineralization rate constants increased with the DO concentration. Owing to the mineralization of MCB occurs through the intermediates, a simplified twostep consecutive kinetics can be used to describe the photocatalytic degradation in $\mathrm{UV} / \mathrm{TiO}_{2} / \mathrm{O}_{2}$ photocatalysis. For the $\mathrm{UV} / \mathrm{TiO}_{2} / \mathrm{H}_{2} \mathrm{O}_{2}$ photocatalysis, $\mathrm{H}_{2} \mathrm{O}_{2}$ of lower dosage acted as electron acceptor to enhance the degradation efficiency. When the dosage was high, however, the degradation was suppressed due to the capture of $\cdot \mathrm{OH}$ radicals and the competitive adsorption of $\mathrm{H}_{2} \mathrm{O}_{2}$. In order to abate the disadvantages caused by using a higher $\mathrm{H}_{2} \mathrm{O}_{2}$ dosage, sequential replenishment of $\mathrm{H}_{2} \mathrm{O}_{2}$ into $\mathrm{UV} / \mathrm{TiO}_{2}$ system was performed. Experimental results demonstrated that both degradation and mineralization efficiencies were enhanced by the restraint of the capture of $\cdot \mathrm{OH}$ radicals, the additional $\cdot \mathrm{OH}$ radicals caused from the second stage addition of $\mathrm{H}_{2} \mathrm{O}_{2}$, and the participation of oxygen in photocatalytic degradation.

\section{Acknowledgment}

The authors would like to thank the National Science Council, R.O.C. for financial support of this study under Contract no. NSC 90-2211-E-238-003.

\section{References}

[1] U. G. Akpan and B. H. Hameed, "Parameters affecting the photocatalytic degradation of dyes using $\mathrm{TiO}_{2}$-based photocatalysts: a review," Journal of Hazardous Materials, vol. 170, no. 2-3, pp. 520-529, 2009.

[2] J. M. Herrmann, "Heterogeneous photocatalysis: fundamentals and applications to the removal of various types of aqueous pollutants," Catalysis Today, vol. 53, no. 1, pp. 115-129, 1999.

[3] G. Balasubramanian, D. D. Dionysiou, M. T. Suidan, I. Baudin, and J. M. Laîné, "Evaluating the activities of immobilized $\mathrm{TiO}_{2}$ powder films for the photocatalytic degradation of organic contaminants in water," Applied Catalysis B, vol. 47, no. 2, pp. 73-84, 2004.

[4] M. N. Chong, B. Jin, C. W. K. Chow, and C. Saint, "Recent developments in photocatalytic water treatment technology: a review," Water Research, vol. 44, no. 10, pp. 2997-3027, 2010.

[5] U. Stafford, K. A. Gray, and P. V. Kamat, "Photocatalytic degradation of organic contaminants: halophenols and related model compounds," Heterogeneous Chemistry Reviews, vol. 3, no. 2, pp. 77-104, 1996.

[6] T. Zhang, T. Oyama, S. Horikoshi, J. Zhao, N. Serpone, and H. Hidaka, "Photocatalytic decomposition of the sodium dodecylbenzene sulfonate surfactant in aqueous titania suspensions exposed to highly concentrated solar radiation and effects of additives," Applied Catalysis B, vol. 42, no. 1, pp. 13-24, 2003.

[7] M. R. Hoffmann, S. T. Martin, W. Choi, and D. W. Bahnemann, "Environmental applications of semiconductor photocatalysis," Chemical Reviews, vol. 95, no. 1, pp. 69-96, 1995.

[8] I. K. Konstantinou and T. A. Albanis, "Photocatalytic transformation of pesticides in aqueous titanium dioxide suspensions using artificial and solar light: intermediates and degradation pathways," Applied Catalysis B, vol. 42, no. 4, pp. 319-335, 2003.

[9] A. Sobczyński, L. Duczmal, and W. Zmudziński, "Phenol destruction by photocatalysis on $\mathrm{TiO}_{2}$ : an attempt to solve the reaction mechanism," Journal of Molecular Catalysis A, vol. 213, no. 2, pp. 225-230, 2004.

[10] K. Chhor, J. F. Bocquet, and C. Colbeau-Justin, "Comparative studies of phenol and salicylic acid photocatalytic degradation: influence of adsorbed oxygen," Materials Chemistry and Physics, vol. 86, no. 1, pp. 123-131, 2004.

[11] T. Hirakawa, K. Yawata, and Y. Nosaka, "Photocatalytic reactivity for $\mathrm{O}_{2}$. - and $\mathrm{OH}$ - radical formation in anatase and rutile $\mathrm{TiO}_{2}$ suspension as the effect of $\mathrm{H}_{2} \mathrm{O}_{2}$ addition," Applied Catalysis A, vol. 325, no. 1, pp. 105-111, 2007.

[12] M. Qamar, M. Saquib, and M. Muneer, "Photocatalytic degradation of two selected dye derivatives, chromotrope $2 \mathrm{~B}$ and amido black 10B, in aqueous suspensions of titanium dioxide," Dyes and Pigments, vol. 65, no. 1, pp. 1-9, 2005.

[13] D. D. Dionysiou, A. A. Burbano, M. T. Suidan, I. Baudin, and J. M. Laîné, "Effect of oxygen in a thin-film rotating disk photocatalytic reactor," Environmental Science and Technology, vol. 36, no. 17, pp. 3834-3843, 2002.

[14] C. H. Wu, "Comparison of azo dye degradation efficiency using UV/single semiconductor and UV/coupled semiconductor systems," Chemosphere, vol. 57, no. 7, pp. 601-608, 2004.

[15] D. S. Bhatkhande, S. B. Sawant, J. C. Schouten, and V. G. Pangarkar, "Photocatalytic degradation of chlorobenzene using solar and artificial UV radiation," Journal of Chemical Technology and Biotechnology, vol. 79, no. 4, pp. 354-360, 2004.

[16] W. Chu and C. C. Wong, "The photocatalytic degradation of dicamba in $\mathrm{TiO}_{2}$ suspensions with the help of hydrogen peroxide by different near UV irradiations," Water Research, vol. 38, no. 4, pp. 1037-1043, 2004.

[17] D. Zhang, R. Qiu, L. Song, B. Eric, Y. Mo, and X. Huang, "Role of oxygen active species in the photocatalytic degradation of phenol using polymer sensitized $\mathrm{TiO}_{2}$ under visible light irradiation," Journal of Hazardous Materials, vol. 163, no. 2-3, pp. 843-847, 2009.

[18] T. L. Villarreal, P. Bogdanoff, P. Salvador, and N. Alonso-Vante, "Photocatalytic oxidation on nanostructured chalcogenide modified titanium dioxide," Solar Energy Materials and Solar Cells, vol. 83, no. 4, pp. 347-362, 2004.

[19] O. Carp, C. L. Huisman, and A. Reller, "Photoinduced reactivity of titanium dioxide," Progress in Solid State Chemistry, vol. 32, no. 1-2, pp. 33-177, 2004.

[20] J. C. Garcia and K. Takashima, "Photocatalytic degradation of imazaquin in an aqueous suspension of titanium dioxide," Journal of Photochemistry and Photobiology A, vol. 155, no. 13, pp. 215-222, 2003.

[21] L. L. Lifongo, D. J. Bowden, and P. Brimblecombe, "Photodegradation of haloacetic acids in water," Chemosphere, vol. 55, no. 3, pp. 467-476, 2004. 
[22] M. S. Dieckmann and K. A. Gray, "A comparison of the degradation of 4-nitrophenol via direct and sensitized photocatalysis in $\mathrm{TiO}_{2}$ slurries," Water Research, vol. 30, no. 5, pp. 1169-1183, 1996.

[23] F. L. Palmer, B. R. Eggins, and H. M. Coleman, "The effect of operational parameters on the photocatalytic degradation of humic acid," Journal of Photochemistry and Photobiology A, vol. 148, no. 1-3, pp. 137-143, 2002.

[24] P. Wongkalasin, S. Chavadej, and T. Sreethawong, "Photocatalytic degradation of mixed azo dyes in aqueous wastewater using mesoporous-assembled $\mathrm{TiO}_{2}$ nanocrystal synthesized by a modified sol-gel process," Colloids and Surfaces A, vol. 384, no. 1-3, pp. 519-528, 2011.

[25] Y. Wang and C. S. Hong, " $\mathrm{TiO}_{2}$-mediated photomineralization of 2-chlorobiphenyl: the role of $\mathrm{O}_{2}$," Water Research, vol. 34, no. 10, pp. 2791-2797, 2000.

[26] C. Adán, J. Carbajo, A. Bahamonde, and A. MartínezArias, "Phenol photodegradation with oxygen and hydrogen peroxide over $\mathrm{TiO}_{2}$ and $\mathrm{Fe}$-doped $\mathrm{TiO}_{2}$," Catalysis Today, vol. 143, no. 3-4, pp. 247-252, 2009.

[27] L. Tatti, D. Niego, F. Rota et al., "Mathematical modelling of pilot-plant photomineralization of chlorophenols in aqueous solution, by photocatalytic membranes immobilizing titanium dioxide," Chemosphere, vol. 34, no. 1, pp. 41-49, 1997.

[28] K. H. Wang, Y. H. Hsieh, and L. J. Chen, "The heterogeneous photocatalytic degradation, intermediates and mineralization for the aqueous solution of cresols and nitrophenols," Journal of Hazardous Materials, vol. 59, no. 2-3, pp. 251-260, 1998.

[29] Y. Ku, R. M. Leu, and K. C. Lee, "Decomposition of 2chlorophenol in aqueous solution by UV irradiation with the presence of titanium dioxide," Water Research, vol. 30, no. 11, pp. 2569-2578, 1996.

[30] F. Rota, M. Cavassi, D. Niego et al., "Mathematical modelling of photomineralization of phenols in aqueous solution, by photocatalytic membranes immobilizing titanium dioxide," Chemosphere, vol. 33, no. 11, pp. 2159-2173, 1996.

[31] N. Daneshvar, D. Salari, and A. R. Khataee, "Photocatalytic degradation of azo dye acid red 14 in water: investigation of the effect of operational parameters," Journal of Photochemistry and Photobiology A, vol. 157, no. 1, pp. 111-116, 2003.

[32] D. D. Dionysiou, M. T. Suidan, I. Baudin, and J. M. Laîné, "Effect of hydrogen peroxide on the destruction of organic contaminants-synergism and inhibition in a continuousmode photocatalytic reactor," Applied Catalysis B, vol. 50, no. 4, pp. 259-269, 2004.

[33] I. Ilisz, Z. László, and A. Dombi, "Investigation of the photodecomposition of phenol in near-UV-irradiated aqueous $\mathrm{TiO}_{2}$ suspensions-I: effect of charge-trapping species on the degradation kinetics," Applied Catalysis A, vol. 180, no. 1-2, pp. 25-33, 1999.

[34] I. Poulios, M. Kositzi, and A. Kouras, "Photocatalytic decomposition of triclopyr over aqueous semiconductor suspensions," Journal of Photochemistry and Photobiology A, vol. 115, no. 2, pp. 123-129, 1998.

[35] J. C. Yu, T. Y. Kwong, Q. Luo, and Z. Cai, "Photocatalytic oxidation of triclosan," Chemosphere, vol. 65, no. 3, pp. 390399, 2006.

[36] V. K. Gupta, R. Jain, S. Agarwal, and M. Shrivastava, "Kinetics of photo-catalytic degradation of hazardous dye Tropaeoline 000 using $\mathrm{UV} / \mathrm{TiO}_{2}$ in a UV reactor," Colloids and Surfaces A, vol. 378, no. 1-3, pp. 22-26, 2011.

[37] E. R. Bandala, S. Gelover, M. T. Leal, C. Arancibia-Bulnes, A. Jimenez, and C. A. Estrada, "Solar photocatalytic degradation of Aldrin,” Catalysis Today, vol. 76, no. 2-4, pp. 189-199, 2002.
[38] E. Bizani, K. Fytianos, I. Poulios, and V. Tsiridis, "Photocatalytic decolorization and degradation of dye solutions and wastewaters in the presence of titanium dioxide," Journal of Hazardous Materials, vol. 136, no. 1, pp. 85-94, 2006.

[39] J. Chen, M. Liu, J. Zhang, X. Ying, and L. Jin, "Photocatalytic degradation of organic wastes by electrochemically assisted $\mathrm{TiO}_{2}$ photocatalytic system," Journal of Environmental Management, vol. 70, no. 1, pp. 43-47, 2004.

[40] T. Velegraki, I. Poulios, M. Charalabaki, N. Kalogerakis, P. Samaras, and D. Mantzavinos, "Photocatalytic and sonolytic oxidation of acid orange 7 in aqueous solution," Applied Catalysis B, vol. 62, no. 1-2, pp. 159-168, 2006.

[41] B. J. P. A. Cornish, L. A. Lawton, and P. K. J. Robertson, "Hydrogen peroxide enhanced photocatalytic oxidation of microcystin-lR using titanium dioxide," Applied Catalysis B, vol. 25, no. 1, pp. 59-67, 2000.

[42] T. Hirakawa and Y. Nosaka, "Properties of $\mathrm{O}_{2}^{--}$and $\cdot \mathrm{OH}$ Formed in $\mathrm{TiO}_{2}$ aqueous suspensions by photocatalytic reaction and the influence of $\mathrm{H}_{2} \mathrm{O}_{2}$ and some ions," Langmuir, vol. 18, no. 8, pp. 3247-3254, 2002.

[43] T. Sauer, G. Cesconeto Neto, H. J. José, and R. F. P. M. Moreira, "Kinetics of photocatalytic degradation of reactive dyes in a $\mathrm{TiO}_{2}$ slurry reactor," Journal of Photochemistry and Photobiology A, vol. 149, no. 1-3, pp. 147-154, 2002.

[44] S. Lodha, A. Jain, and P. B. Punjabi, "A novel route for waste water treatment: photocatalytic degradation of rhodamine B," Arabian Journal of Chemistry, vol. 4, pp. 383-387, 2011. 


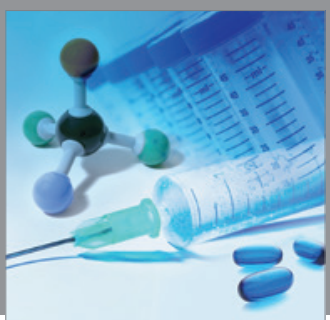

International Journal of

Medicinal Chemistry

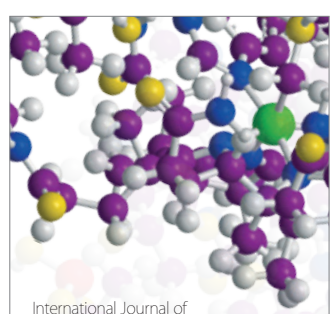

Carbohydrate Chemistry

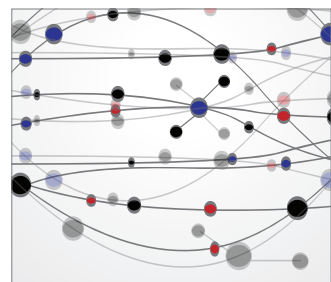

The Scientific World Journal
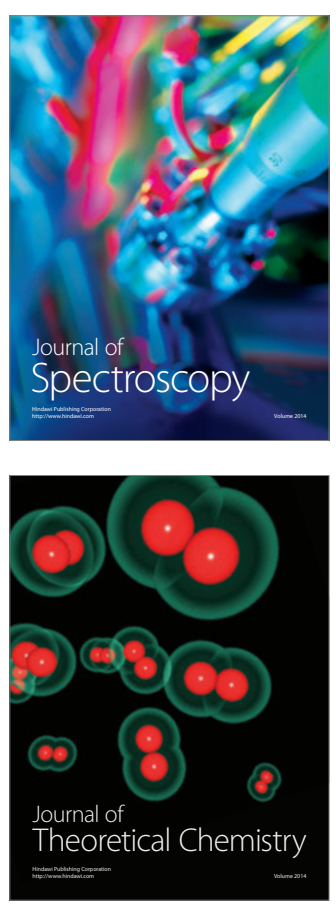
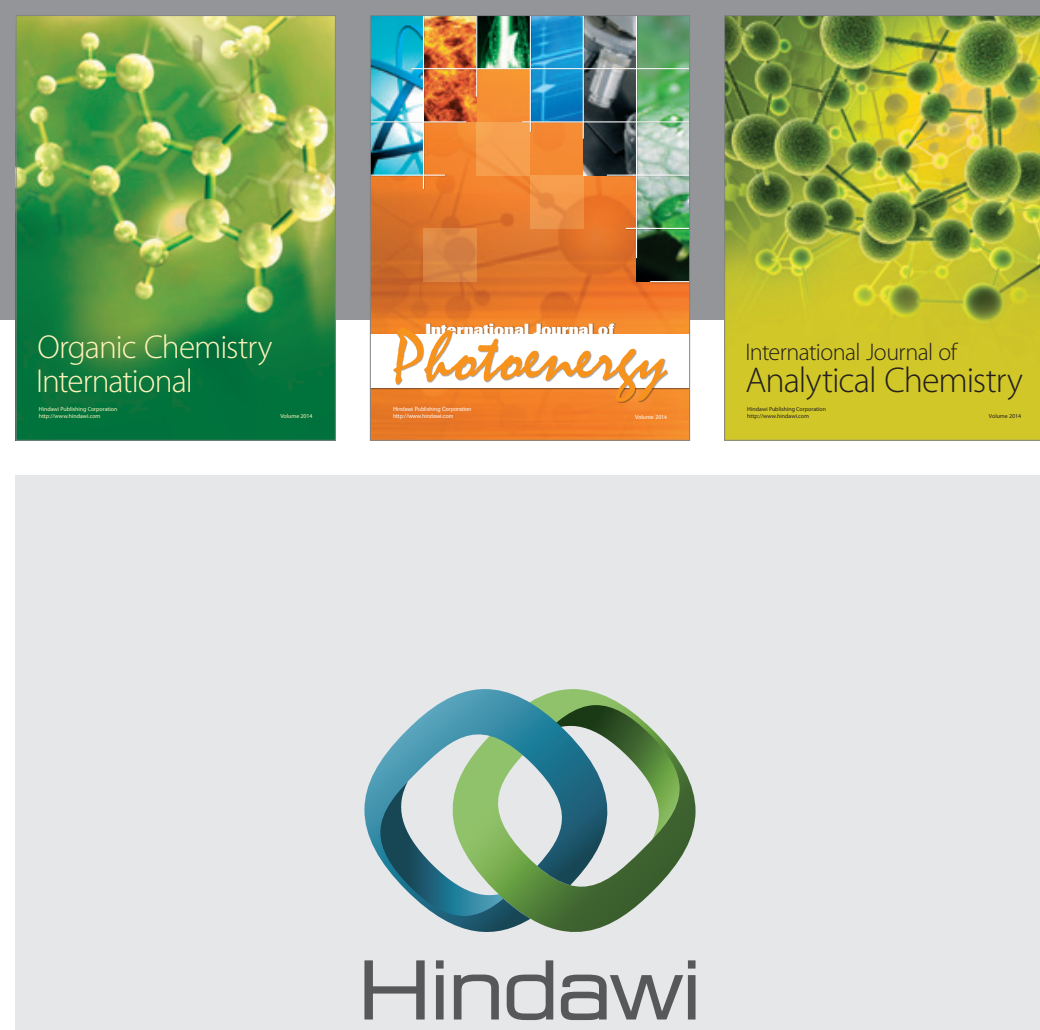

Submit your manuscripts at

http://www.hindawi.com
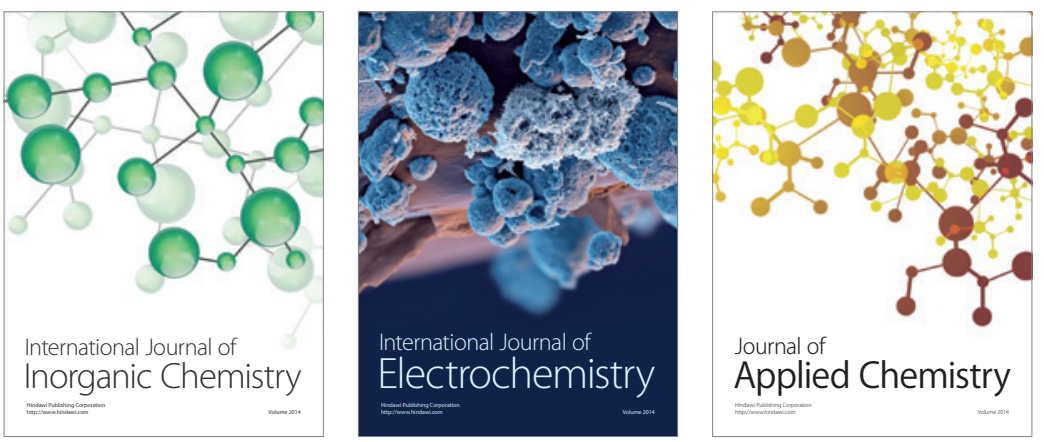

Journal of

Applied Chemistry
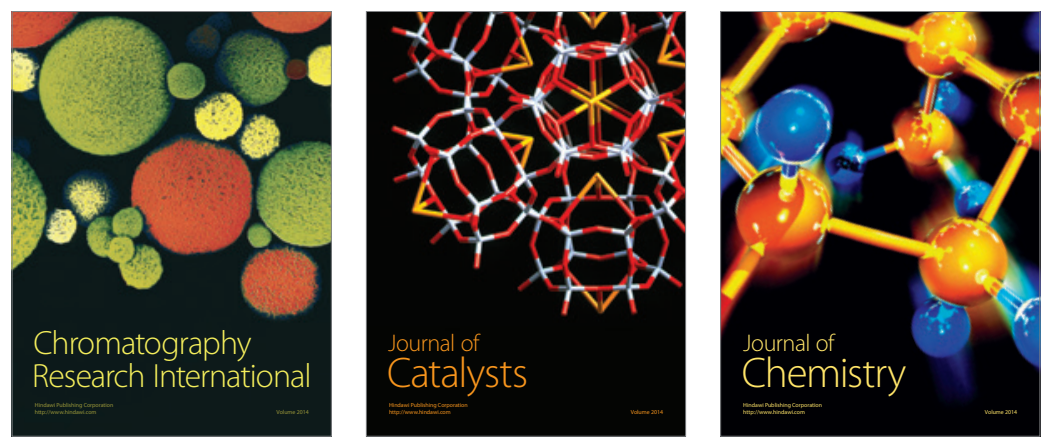
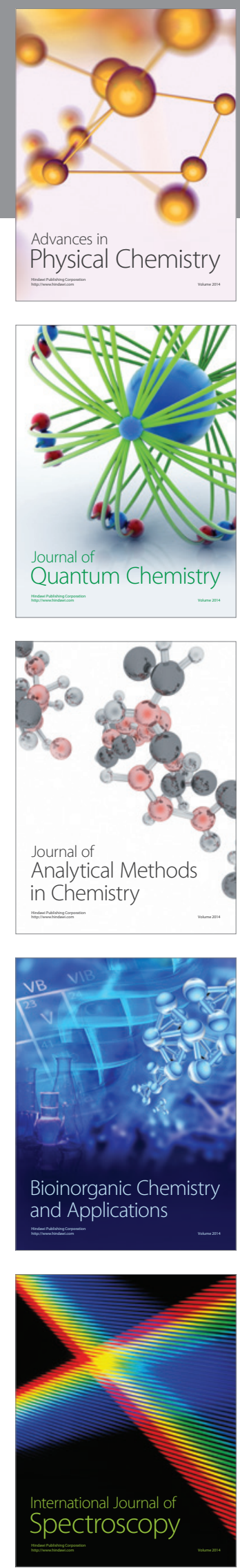